\title{
Social Change and Development: A Critical Comparison of Classical with Contemporary Sociological Theory
}

\author{
Idris Guclu ${ }^{1, *}$ \\ ${ }^{1}$ Independent scholar, Ankara, Turkey \\ *Correspondence: Independent scholar, Ankara, Turkey. E-mail: idrisguclu@yahoo.com
}

Received: June 6,2019 Accepted: July 19,2019 Online Published: September 19, 2019

doi:10.5430/sass.v6n2p66 URL: https://doi.org/10.5430/sass.v6n2p66

\begin{abstract}
This study re-examines the prevalent view of classical social theorist, Auguste Comte and contemporary social theorist, Gerhard Lenski. Both social theorists are important figures in terms of social change and social development. Therefore, within context, the notion of social change theories, its relations and cause of social change are discussed, followed by an outline of the concepts of both theorists. Next, it deals with what the two perspectives share in common and compares the differences between them. The study revealed that the two perspectives are fundamentally different because Comte focused on the development of human thought while Lenski focused on social change and development as a result of technology. In this respect, the determinants of social change and development emerge from within society itself; the deepest and the most important disagreement lies between those who see the mental or spiritual evolution of society as the main driving force of history and those who see the role of technology as its root cause.
\end{abstract}

Keywords: Auguste Comte, Gerhard Lenski, social change, development, progress, technology

\section{Introduction}

The technology and information revolution experienced in the 20th century has become the most important phenomenon in the social life. Today, the sciences and their practice were decisive factors throughout the 18th, 19th, and 20th century, driving change in all other social phenomena and institutions. Seemingly constant improvements in transportation and communication leave the world feeling smaller and smaller and gives the nature of change a global character. The effects of globalization and social change have led society to dissolve many old institutions and their forms. In fact, the human environment alters noticeably with each new generation. For instance, trends, customs, traditions, beliefs and experiences follow each other and their reflections are seen in the social structure. The prevalence of new innovations and changes with each new generation can be found in communication, education, production and consumption patterns, war, law, art, government, family life, taxation, leisure time activities, clothing, and in individual behavior; in short, in every field (Smith, 1996). This indicates economic and technological changes in the political and intellectual equally well.

According to Sorokin, "to know social change for sociology is important as to know blood circulation for physiology". From this point, social change is a change in the social structure (Bottomore, 1977:392). Thus, Changing one of the elements in the social structure leads to change others like a domino effect change. Because there is an inter-relationship and integrity among social structure elements (Kıray, 1999).

Social change takes place gradually. After a certain degree it is seen occuring a whole structural change. Social change, albeit to varying degrees, will be forced to inflict on each side of the so-called functional whole social structure changes in a certain direction. Therefore, every society is always in a state of change, but in the case of natural interdependent institution is a system that always had to be in balance regerding the relevance and value (Özdemir, 1988).

In short, growth, individuality, communication, the organization on behalf of each other to build the idea of wrapping the process of social mobilization has more need for social change theories. In this case, the right concept helps us in removing surfaced that really what being.

In the confusing details of the massive complex of social procedures, overbearance and narrowed the voice of social 
life noise in various foreground and background, different instruments, the pulse of life, to hear the melodies and rhythms of "simply confusion in the other side" We have developed ourselves to explore (Reeler, 2007:2).

As sociologists, our task is to ask more systematic and careful pioneer questions in order to understand these developments and changes, and to explain the theory of communication and organization that will help us to understand them. Therefore, the aim of this paper is to discuss social change and development in terms of comparing and contrasting a classical perspective with a modern perspective. The concept of social change and development will be discussed first.

\section{Social Change and Development: Concepts, Theories and Its Relations}

Social change, in its most general sense, can be described as a social structure consisting of relationships and institutions that change from one period of time to another. It means the exchange of human to human and human to nature relationships alters throughout the entire social structure. Social change can be defined as the exchange of material life in the sense that it overlaps with this system (İsgüden et al., 1995). Social change refers to change in the social structure while social development results in the transformation of the social structure.

The idea that there is a relationship between each of the variables constituting the social structure is very important in terms of understanding social change. In this sense, no variable constituting a society has meaning solely in itself. Each variable becomes meaningful only in relation to the others. For instance, it will be impossible to understand the phenomenon of production when we ignore the consumer.

Social change can be observed in short time intervals and consists of auditable conversion (Doğan, 2002, p. 222 cited from Rocher, 1968). It is thus possible to examine and observe social change in a geographic area or in a socio-cultural environment as it is happening. Before going into details, it is useful to mention the differences in the concepts of change, progress, development, and evolution, since they are often used like synonyms.

Indeed, it has been seen that Giesen's stability and order (Exceptions do not break the rules) and based on the order of evolving ideas, has existed for thousands of years. The extraordinary dynamism of the French Revolution and the Industrial Revolution were the most important periods. These two facts also help us to understand the dynamic concept of social change.

According to Luhmann, "change was known as a property of the social order" (Haferkamp \& Smelser, 1992, p. 2 cited from Luhmann, 1984: 471). Hermann Strasser and Suscan C. Randall both determined the following attitudes regarding social change: "magnitude of change, time span, direction, rate of change, amount of violence involved". That is, all theories of change but must contain the following three elements to explain the other: 1) Structural determinants of social change: population mobility, change of place caused by the war, strains or contradictions; 2) Processes and mechanisms of social change: such as political disagreements and social movements; 3) Directions of social change: structural modifications, impacts, and outcomes (Haferkamp \& Smelser, 1992: 2-3).

Social change is often described as a development, referring to the hit potential, open itself or resulting in changing things. Change describes a condition. As Leibniz indicated, all beings have the potential to create a new state in the formation of the future. They naturally follow a specific process without any obstacles (Bock, 1997). On the other hand, there is a close relationship between the concepts of modernization and change. Sociologists have generally accepted that the modernization refers to the the process of underdeveloped society passing into modern or western society. Thus, social change is sometimes called called modernization (Kongar, 1981).

Whereas social change covers any change, social development refers to a positive distance covered in a specific area. According to Jacobs and Cleveland (1999:5), social development is defined as "the release and channeling of social energies through more complex social organization to enhance productive capacity and achieve greater results". Examples of social development can be counted as follows; increases in economic prosperity, development of manpower and resources, expansion of the middle class, the establishment of rational thinking habits, a rise in socio-cultural level, etc. Therefore, the concept of development involves a conscious effort. This effort operates in the desired direction. But the concept of development is not always the same for everyone in a given social direction and is influenced by their unique values. For example, the spread of Western lifestyle with modernization is considered a positive development for some. For others it is considered as a degradation and dissolution (Doğan, 2002). Speculation on the development concept is emerging in the development and evolution of the concepts when considered together. The social evolution concept was used in the nineteenth century. It was inspired by the philosophy of history, which strongly reinforced the theory of biological evolution. It was seen as a solution for applying the concept of biological phenomena to social issues. 
Like Ogburn, contemporary sociologists draw attention to the difference between biological and social evolution theory. According to Ogburn, the law of elimination, inheritance, and speciation in the evolution of social institutions yielded little result that can be considered as vital or important (Ogburn, 1922). The theory of evolution still maintains the charm of the paradigm of existence. In sociology, this historic controversial theory has made a remarkable contributation to a fenomenlik floor. Such evolutionist thought can be seen in the writings of American sociologist Talcott Parsons (1961, 1966, 1967, 1971, 1977), Neil J. Smelser (1959, 1976), Gerhard Lenski $(1970,1976)$, Germany sociologist Jürgen Habermas (1976, 1981), and Niklas Luhmann (1984). In addition, evolutionists thought has the same effect on the study of Shmuel N. Einstadt $(1970,1976)$. These evolutionary ideas naturally received their own criticisms. Parsons used the environment and the gaining of more independence in terms of storage capacity under a control environment. Parsons, presumably due to failure of the structural prerequisites necessary for the continuity of teleoj description and evolution of the formula, continues to receive such criticism. A new idea on evolutionist thoguht by German sociologists has also joined its critical response (Habermas, see Berger, 1982; Schmid, 1981; Honneth and Joas, 1986. Luhmanda, see Haferkamp and Schmid, 1987). According to Schmid (1981), Habermas's work, in particular, is prim and proper, and can not be sufficiently descriptive. He further said that Habermas's work can be unsuccessful in finding reasonable cause in terms of an increase in moral thinking and the adaptability of a social formation.

The idea of progress in the works of Aristoteles, Agustinus, Fontenelle, Saint-Pierre, Condorcet, Comte, Spencer, and Tylor detailed and includes a comprehensive image in change. This indicated the precise and original interpretation of social and cultural differences. It also means that the differences can be used within the construction theories of cultural change (Bock, 1997).

As mentioned above, social change refers to a transition in progress toward a new and completely different situation, differing from prior institutions consisting of the current situation in the social structure and social relations. The concept of social change points to a conscious effort for development and progress because it does not include whether the new social structure is better or worse. In this sense, it can be said that social change can be forwards and backwards. The human being is located at the focal point of social change. There is no doubt that social change cannot be an entirely irreducible human element. Change is a process that is constantly beginning and developing. It can also be said that change is a necessary element of the time dimension. Besides of these two elements of social change, the formation of the spatial dimension is the third important element taken into consideration. This element can be considered as an essential element for development whenever a change occurs in a particular physical environment (Doğan, 2002). Thus, it can be defined as events that changed the course of history. Finally, "both terms refer to the process of change in social structures, which results in producing a newly evolved higher consciousness or a new type of society, culture or way of life" (Guclu \& Sevinc, 2011: 139).

\section{Causes of Social Change}

Today, different views about the condition affecting social change take place in the literature. For example, Giddens pointed out that three main factors that affect social change; a) permanent physical environment, b) political organizations, and c) cultural factors. In addition, there are economic factors behind social change (Giddens, 2000). Generally, social scientists have focused on the factors of technology, demography, economics, culture, and the environment to determine which causes social change more often. The main factors that play a role in the movement of social change can be examined under the following headings:

1. Demographic factors: Population movements are among the factors affecting the structure of society. Population plays an important key role in the formation of social change. Norms, values and the formation of the organization cause conflict and competition among and within societies regarding the social relations of their social institutions. Population is not a constant value because it is constantly increasing and decreasing. Therefore, population size is one of the most important dimensions of a dynamic society (Yaka, 2011). Inability to control the distribution of wealth and opportunities within the population leads to the emergence of imbalance. Failing to provide sufficient services, including education and healthcare, to the entire population of necessary production communities causes many problems. For this reason it is necessary to control and plan the population (İçli, 2011).

2. Geographic factors: The geographical environment is changing constantly, both by the effects of nature and by human construction. Even society's eating habits, shelter design, and clothes are affected by geographical factors. Many events occurring in the natural environment affect society; such as earthquakes, droughts, climate, floods, erosion etc. People's lives, in the case of natural deterioration or lack sufficient stability, can be affected in a negative way and is closely related to the geographical conditions of the natural environment. Humans attempt to control the 
natural environment in order to minimize the uncertainty from geographical conditions.

3. Technological factors: The development of technology is one of the important determinants of social structure leading to major social change. Technology has a direct impact on social change, such as controlling nature and the development of human relations. As Daniel Bell stated, today's society has become a "global village" owing to the influence of communication technology. The great tradition of theoretical sociology also emphasizes different types of electronic media. For instance, according to the Durkheimian sociologists, while broadcast media like radio and television disseminate ideas, individual communication tools (eg. telephone) strengthen more natural ideas and views. Marxist tradition focused on the booster effect from the media by politicians and the cultural hegemony. Weberian thought seeks rational reasoning for the narrowing of time and the boundaries of space. Here, media promotes the elements culture. Many studies (eg. McLuhan 1967, Eisenstein 1979) offering perspectives on digital media note that the new organized parts of media is trying to uncover the sense of differentiated capabilities and enabling new forms of communication, in turn, causing social change (DiMaggio an et al., 2001).

4. Cultural factors: The attitudes of individuals and the variations occurring in their behavior and thinking both also lead to social change. These variations are centered on the varaibility of technology. Even the simplest of developments in mass media leads to changes in individual attitudes and behavior, one major example is the internet (İçli, 2011). Castells (2008) recently stated that the world has recently entered the "Information Age". He further stated that digital information technology is a network capable of reducing the spread everywhere social structure as the simplest forms. According to Castells, written, verbal and video materials on the Internet come together under one roof as images creating a society essentially based on a new form of identification. The interent has built a new type of social organization.

5. Social Environment: Political agreements, such as the battle for influence over the world of a group or society, affects social life and leads to social change. In particular, changing and growing social movements since the 1970s have contributed to changes in the traditional state of political and economic democracy, civil society and non-democratic transition in the expansion and even contribute to the deepening redefinment of democracy (Fuantes \& Frank, 1990). Problems with existing social relations in a society can accumulate and start a process of change over time. These problems usually affect certain specific social groups; such as communities, nation, class, racial, ethnic and gender groups, religious and political groupings and etc. The process may cause some people to question the status quo regarding some aspects of the insider or rejection. The process becomes a social one when various groups of people discover that they have lived similar experiences, pointed to the like problems, asked the same questions, and tended to offer similar objections. After that, groups are led into relationships with with others and to a new broader identity. This is also a process that will be isolated and tranfered to a social process (Brecher, Costello \& Smith, 2002).

If we look at the theories and their various classifications for social change, we see those classifications covering both linear and cyclical change. The linear persepctive is basically evolutionary theory, or rather, a social evolution perspective. All human societies are described through development and evolution as a general phenomenon. Phase experienced (savagery, barbarism and civilization) by mankind and human society are described with common criteria. These criteria, including heredity, extracting, and speciation, are the theories. Comte, Spencer, Hobhouse and Marx are the leading representatives of this theory. According to Bottomore (1996), the linear theory has been very useful for explaining numerous important changes in mass and social history of mankind. According to cyclical theories, The change has been explained as rhythmical or cyclical ups and downs. Vilfredo Pareto, a leading figure of this approach, developed the theory of the Cycle of Elites (Pareto, 1991). He is one of the first cyclical theoriests in sociology. Pitirim Sorokin, Oswald Spengler and Arnold Toynbee are also famous for this notion. Pareto (1935), in his famous book, titled "The Mind and Society" pointed out that social change centered on political power formed from the struggle between them. Pareto's theoretical approach is based on the theories of Ammon and others, which were dreived from the perceptions of biological differences regarding groups in society during their time.

However, few historical events have been found to support this theory. Pareto focused on a single example of the circulation of elites, ancient Rome, and completly ignored the development of modern democratic methods. It does not seem possible at this time that the linear and cyclical perspectives can be merged into one single perspective, even though there are some common characteristics between them. These can be called as eclectic (selective) theories. Ogburn's theory of cultural lag can be an example for that. Ogburn states that societal changes emerged at the end of the cultural evolution. Invention, adaptation, accumulation, and dissemination are the terms used to explain the cultural evolution (Doğan, 2002).

Theories of social change center on universal laws that govern such changes. A new theory of social change is considered necessary, from time to time, when the old theories are no longer adequate to describe current universal 
laws. Evolutionary approach has, so far, become the most prominent among them (Giddens, 1999).

Social change is a social phenomenon and a natural social process. Change is not only formed by the internal structure within a society, but is also formed by factors outside of it. This change can be sometimes be slowed down, hampered, perhaps even redirected some, but not stopped completly. Change is sometimes fragmentary and institutional, and is sometimes integrated. Change contains items related to individual, social and physical space. Therefore it is not one-way orone-dimensional and is not based on one single factor. Rather it is very complex, and very motivated social process. Social change is a multifactorial process. In conclusion, social change is a cumulative social movement. All small and large social changes in society are necessarily based on the previous changes and, therefore, resulting from them. Likewise, many functionalist theories of social change and social development also made a connection to prior empirical trends (Hagen-Zanker, 2008).

Positive and negative short term changes in a local community's overall social evolution is not entirely due to outside influences. Each phenomenon of social change makes a contribution to global changes in the long term as well. Thus, there are many factors influencing society toward social change.

\section{Auguste Comte's Perspectives on Social Change and Development}

Comte explains social change and development throughout history by classifying the theoretical conditions of knowledge resulting from social progress. According to Comte, all societies pass "successively through three different theoretical conditions: the theological, or fictitious; the metaphysical or abstract; and the scientific, or positive" (Lenzer, 2004:71). Societies, sciences, individual minds, arts, and groups go through this process. For Comte, the development of society is related to the evolution of mind through the laws of these three stages (Guclu \& Sevinc, 2011). He sees social dynamics as a process of progressive evolution in which people become cumulatively more intelligent, as in the following:

From the study of the development of human intelligence, in all directions, and through all times, the discovery arises of a great fundamental law, to which it is necessarily subject, and which has a solid foundation of proof, both in the faces of our organization and in our historical experience. (Lenzer, 2004: 71)

Social change and development is a process. This process is one that people can modify or accelerate, but in the end the laws of progressive development dictate the development of society.

Auguste Comte analyzed social change and development from an historical perspective. Each stage of human development points out a level of understanding. Consequently, each stage moves from the lower level of intellectual development of society to the next higher level of society stages (Guclu \& Sevinc, 2011). Yet, each stage is dynamic rather than static. "Each coming stage overshadows the previous stage and renders it outdated; the newer stage grows and becomes more complex and develops due to the increased capacity of the human mind" (Guclu \& Sevinc, 2011: 139).

As is well known among sociologists, Comte introduced the organismic analogy to sociology. Comte argued that the development of society is both the reflection of the progress of the individual mind and an indirect result of it (Guclu \& Sevinc, 2011). He uses a metamorphosis of an individual's own history to show how society passes through three stages:

The point of departure of the individual and of the race being the same, the phases of the mind of a man correspond to the epochs of the mind of the race. Now, each of us is aware, if he looks back upon his own history, that he was a theologian in his childhood, a metaphysician in his youth, and a natural philosopher in his manhood. All men who are up to their age can verify this for themselves. (Lenzer, 2004: 73)

He evaluates society with the growth of human beings and focuses on intellectual factors. Comte's concept of social change and development can be seen in Figure 1. 


\section{Law of Three Stages}

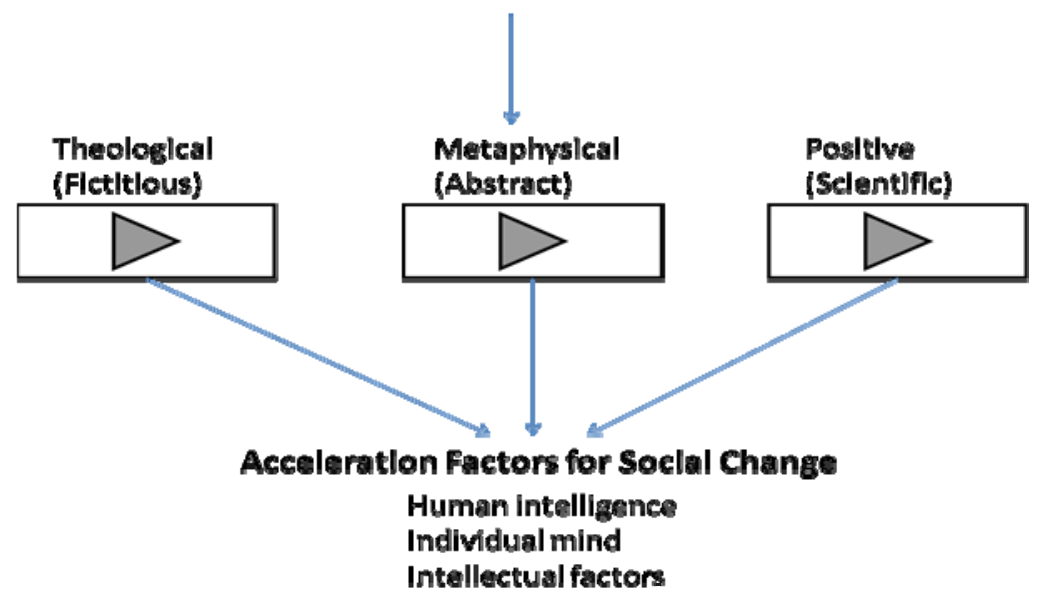

Figure 1. Comte's Theory of Human Progress

The theological stage is first. As mentioned above, at this stage, societies are founded in a child-like state of development. Societies are naïve. Men manipulated by their imagination seek out justifications for all phenomena in the will of supernatural beings that they visualize mythically. Natural and social phenomena are explained through supernatural beings.

In this first stage, there are several gods in which people believe. For instance, the ancient Egyptians believed in many different gods and goddesses and explained reality as a result of the will of these gods and goddesses. Some of these gods were responsible of the creation of human beings, some brought the flood, and some were responsible of the protection of people, and so on. To Comte, such people "[supposed] all phenomena to be produced by the immediate action of supernatural beings" (Lenzer, 2004: 72). Here, the physical and social world is seen as produced by supernatural beings. There is the lack of scientific knowledge and explanations about the functions of the natural world. People's knowledge is based on direct observation with unexplained gaps filled in and explained away by the direct intervention of gods. Comte explains that the "theological system arrived at the highest perfection of which it is capable when it substituted the providential action of a single Being for the varied operations of the numerous divinities that had been before imagined" (Lenzer, 2004: 72). In brief, the theological stage characterized the world prior to 1300 .

As society develops and mental thought matures, society will replace the theological stage with the metaphysical or abstract stage. Therefore, social development reaches its peak at the previous stage and is replaced with a higher level of evolved sensibility - the metaphysical stage. In this stage, people seek a justification for phenomenon in the forces of nature, specifically in the fundamental force and the chemical force, meaning this epoch is characterized by nature rather than gods and goddesses. The development of society at this stage occurred approximately between 1300 and 1800. Comte explains this stage as follows:

In the metaphysical state, which is only a modification of the first, the mind supposes, instead of supernatural beings, abstract forces, veritable entities (that is, personified abstractions) inherent in all beings, and capable of producing all phenomena. What is called the explanation of phenomena is, in this stage, a mere reference of each to its proper entity. (Lenzer, 2004: 72)

In this stage, societal knowledge does not see gods as the cause of all natural and physical phenomena. According to Comte, "men substitute one great entity (Nature) as the cause of all phenomena, instead of the multitude of entities at first supposed" (Lenzer, 2004: 72). However, this does not mean they have the tools and knowledge to explain social phenomena and understand its laws. While people do not know the science behind the weather or fully understand weather patterns, they now realize that the gods are not crying and causing rain, but simply that the clouds are raining.

As we have seen, the social change and development in the first two stages are modeled by the intellectual level of society. While the gods are responsible for social phenomena in era one, "nature" is primarily responsible for social 
phenomena in era two and for what was unknown in era one. Thus, to Comte, the turning point is when people credit phenomena to nature instead of gods.

When the world finally entered positive stage it was characterized by belief in sciences. In this stage, "the mind has given over the vain search after absolute notions, the origin and destination of the universe, and the causes of phenomena, and applies itself to the study of their laws-that is, their invariable relations of succession and resemblance" (Lenzer, 2004: 72). Now, only logical explanations are accepted; all reasoning other than material world will be refused. Now, the laws of nature are not justifications of phenomena but descriptions of them. Instead of searching for absolute truths, people concentrate on observations of the social and physical world, and then apply scientific methods for understanding the laws that govern them. That is, people start to understand the scientific laws that control the world and reasoning and observation are the primary means for doing so at this stage.

With the coming of the positive stage, sciences developed rapidly compared to the first two stages. Comte saw science arising from prevision, and prevision arising from action. Each new scientific field relies on the emergence of a previous scientific field and the development of science depends on this deterministic chain. In this respect, some sciences followed others. For example, Astronomy was the first developed natural science, followed by physics, chemistry, biology, and finally, sociology with mathematics supporting it all. In brief, Comte believed that the positive stage is the final stage of this linear progress. Society will use the human reasoning to organize itself when the proper time comes. All in all, Comte had a linear approach to social change.

Comte extends the static and dynamic conditions of the subject to social science. While the former focuses on the harmony of the conditions, the latter studies the progress and the change in society. Comte said, "the study of social statics is at once more simple, more general, and more abstract than that of social dynamics" (Lenzer, 2004: 390). He also added that "social dynamics studies the laws of succession, while social statics inquires into those of coexistence" (Lenzer, 2004:230). Comte's theory of social dynamics is founded on the three intellectual stages.

Comte's studies on social evolution focus on Western Europe, which he viewed as the most highly developed part of the world during the nineteenth century. He also discussed the division of labor, which has a positive effect on the development of society because it promotes interdependence. Besides fostering human solidarity, the division of labor also allows for the development of individual gifts and capacities. Therefore, positivism was seen by Comte as both advanced science and social change. Comte believed that social change will result as the progress of society; society will be in a better position than before the positive stage.

According to Comte, social changes happen, but maintaining the social order is necessary in order to reach a higher stage. He claimed that there is not a revolution but a gradual transition. In this respect, "only improvement and modification in correspondence with the veritable nature of the existing order and its historical development are possible" (Lenzer, 2004: xlvii).

In summary, Auguste Comte's historical perspective analyzes social evolution from the perspective of society maturing mentally. From the naïve, child-like stage where the gods are attributed responsibility for all natural phenomena, through the metaphysical to the final positive stage, societies evolve to a maturity that has the ability to comprehend the laws that govern science. Therefore, Comte's law of three stages suggests that science is the key point for social development. In addition, for Comte, human knowledge, which is the driving force of progress, passes through these stages.

\section{Gerhard Lenski's Perspectives on Social Change and Development}

Gerhard Lenski determined that technological progress is the primary factor driving social change and development (Guclu \& Sevinc, 2011). Lenski's explanation of societal development is related to the level of technology that a society has used. Actually, Lenski's neo-evolutionary theory emphasized the various stages of societal development as influenced by subsistence technology, which was first presented in his well-known book Power and Privilege, which analyzes the social development addressed to the systems of distribution that society uses. To Lenski, the structure of distributive systems influences his perspective regarding social development. The factor that allows for the accumulation and distribution of surplus wealth is the effective use of technology:

The most basic characteristic of distributive systems do appear to be shaped by the interaction of those constant elements in the human situation which we identified earlier and the variable elements of technology. As hypothesized, the influence of these factors appears to be mediated by a series of social organizational factors whose variation is greatly influenced by prior variations in technology. (Lenski, 1966: 435) 
Gerhard Lenski took a historical perspective for analyzing social change and development. He classifies the historical periods which describe the social evolutionary changes. Lenski specified four stages of societal development regarding to their level of technology adapted (Guclu \& Sevinc, 2011). Hunting and gathering societies were the most primitive societies with little technology at their disposal. Lenski claimed that "Hunting and gathering societies are the most primitive of all human societies, with respect to technology in general and mode of production in particular" (Lenski, 1966:94). Hunting and gathering societies consume a great deal of time, energy, and thought toward collecting and hunting for food. In this type of society, there is no surplus; they are nomadic or seminomadic. There is little division of labor, and they are highly homogenized. Lenski also says these societies:

are invariably small. If societies are defined as socially autonomous populations, then each local bond or community constitutes a spate society. Larger and more complex systems of social organization are virtually impossible at this level of development. (Lenski, 1966: 98)

Lenski states that the next level of society is the horticultural society, delineated by the technology used to grow crops and categorized into simple horticultural societies and advanced horticultural societies (Guclu \& Sevinc, 2011, p.140). According to Lenski (1966), horticultural societies began with sticks for growing food (simple horticultural) then progressed to make use of the hoe, irrigation, crop rotation and so forth (advanced horticultural). In brief, the level of the technology a society adapted into the culture indicated its level of social development. Lenski also noted that social changes or development "begin in the realm of technology and extended into almost every other sphere of life." (Lenski, 1966: 144).

The third type of society is the agrarian society. Like horticulture societies, agrarian society is can be categorized into parts. This epoch introduced a new technological tool to reshape societies, the plow. Lenski underlined the importance of the plow and argued that it "heralded an agriculture revolution. Plowing stirs up those fertile elements in the soil that in semi-arid regions are liable to sink down beyond the reach of plant roots" (Lenski, 1966: 190). A single man can cultivate many areas with the help of a plow and two oxen. No longer is an entire population needed to plant, gather, fish or hunt. Two other major technological developments playing an important role in terms of social change and development, were the wheel and the sail, which greatly enhanced the ability to move the surplus food now produced to those who needed it.

Lenski (1966) went on to say that as societies produced surplus they, in turn, lead to the birth of the division of labor. It was at this stage that power and privilege began to be allocated to certain people and various social classes evolved. The effect of technological advancement is now seen in every strata of society and it led to the development of social stratification.

The next stage was the industrial society, which was a completely new form of society. To Lenski, it was a tremendous change and primarily due to technological advancements in the last two centuries (Guclu \& Sevinc, 2011). The changes in productive systems, techniques of production, and patterns of economic organization laid the foundations for something new and profoundly different, the modern industrial society. Lenski explained the differences were due to: "the raw materials used [were] far more diversified, the sources of energy quite different, and the tools far more complex and efficient" (Lenski, 1966: 298). Lenski's concept of social change and development is illustrated in Figure 2.

The progressive development of societies and related changes are based on the technological advancement. As the technology advances, "every aspect of social life within a society develops and become more sophisticated. In every epoch, all other aspects of life such as culture, sciences, groups, individuals, military, governments, and etc. are influenced by the new technology" (Guclu \& Sevinc, 2011: 139). From this perspective, Lenski says technology influences, guides and brings about social change and development. 


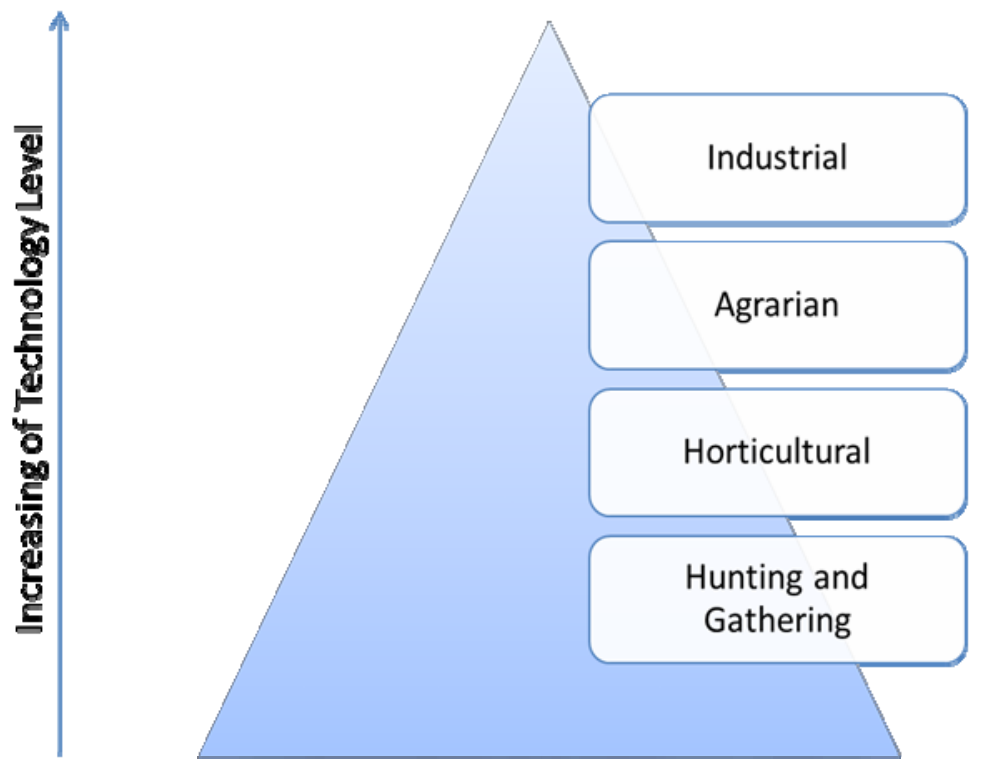

Figure 2. Lenski’s Process of Change

\section{Some Convergences and Central Differences}

Both Comte and Lenski's approaches can be applied to analyzing specific social phenomenon regarding social change and development. In both approaches, there are several similarities explaining social change and development. Both Lenski and Auguste Comte analyzed social change and development from an historical perspective. Each approach depends on the concept that with the passage of time, the society will change through evolution, not revolution.

Comte uses a metamorphosis of an individual's own history to show how society passes through three different theoretical conditions: the theological; the metaphysical; and the positive. Comte explains the development of society with the growth of human beings. That is, when the intellectual level of societies is at lower level, the theological stage. In the metaphysical epoch, a societies' intellectual level is more advanced than the previous stage, but is not as developed as the final, positive phase of human development. Similarly, Lenski outlines the eras of social development. From a historical standpoint, Lenski starts with hunting and gathering societies, successively followed by horticultural societies, agrarian societies and finally, industrial societies. Like Comte's laws of three stages, each epoch of social development was a gradual progression and maturity.

Comte used organismic analogies to describe social changes where society is a social organism that is evolving or developing from a simple organism to a more complex one. Comte's theories concern the development of the human species, from a primitive being to a modern being, and are, therefore, within the concepts of social development. In a similar manner, Lenski's theory outlines how technology shaped societies. As technologies became more sophisticated, so did the society that incorporated them. In this respect, both Comte and Lenski's theories progress from the simple to the complex. The last similarity between two theorists is that each stage or era is replacing and preceding the previous one. Like Lenski, according to Comte, each stage developed and matured in the womb of the previous stage.

We can also see several differences between Comte and Lenski. Comte focused on the development of human thought, whereas Lenski focused on social change and development as a result of technology. For Comte, the mental or spiritual evolution of society is the main factor in social development. But for Lenski, the technology is the most important factor. In brief, Comte's approaches address social change and development in terms of the mental process and maturity of philosophy, while Lenski looks at the issues from the perspective of the technology the society incorporates into their culture. These are the main differences between both theorists.

More noteworthy contrasts include, one, the number of epochs related to societal development. While Comte only identifies three stages of intellectual development, Lenski identifies four main epochs of social development with seven subsets. For example, the horticulture epochs consists of two phases and the last phase of social evolution, the industrial age, is made up of three parts. Like Comte each subsequent phase of social evolution is more advanced than the previous phase. Second, Comte's approach toward social development is more obscure than Lenski's, since 
Lenski's theory provides easily identifiable points in history when technology is introduced and incorporated into society. Finally we can say that Lenski's theory is relatively linear and one dimensional.

\section{Conclusion}

Any society is subject to change in terms of its structure and function and this is unavoidable. Based on a society's structure, the speed of changes within vary. The resistance or acceptance of changes in a society also varies. In this sense, changes are a process and the social change concept is an important consideration in the study of sociology. That is why social scientists, especially sociologists, have been trying to figure out society's process of change, direction, determining factors, and etc. for a long time.

There is no doubt that many scholars define "social change" in unique ways with concepts based on their unique fields and the related perspectives and theories within them. Often, each definition applies a unique meaning to the same term, making it hard to find a common definition across fields. Even across fields there are common concepts on social change. Contemporary sociologist Gerhard Lenski's typology of human societies and classical sociologist Comte's the law of three stages both indicated that social change has an inevitable effect on every aspect of life and that it covers a comprehensive change in the social structure.

Taken together, both theorists have their own approaches addressing social change and development, yet, both perspectives show us that the issue of social change and development in sociology is a very complex. Both theories remain valid and useful to this day, showing that analyzing how a society changes and develops continues to be an important field of study for sociologists.

\section{References}

Bock, K. (1997). İlerleme, Gelişme ve Evrim Kuramları. Sosyolojik çözümlemenin tarihi. Ed. Tom Bottomore- Robert Nisbet. Çev. Aydın Uğur. Ankara: Ayraç Yayınları.

Bottomore, T. (1977). Toplumbilim. Çev. Ünsal Oskay. Ankara: Doğan Yayınevi.

Brecher, J., Costello, T., \& Brendan, S. (2002). Aşağıdan küreselleşme. İstanbul: Aram Yayıncılık.

Castells, M. (2008). A ̆g toplumunun yükselişi. İstanbul: İstanbul Bilgi Üniversitesi Yayınları.

DiMaggio, P., Hargittai, E., Neuman, W. R., \& Robinson, J. P. (2001). Social implications of the internet. Annual review of sociology, 27, 307-336. https://doi.org/10.1146/annurev.soc.27.1.307

Doğan, İ. (2002). Sosyoloji kavramlar ve sorunlar. Ankara: Pegem Yayıncılık.

Fuentes, M., \& Frank, A. G. (1990). Toplumsal hareketler üzerine On Tez. Çev. A. Gürata-T. Bora. Birikim Dergisi, 29-41.

Giddens, A. (1999). Toplumun Kuruluşu. Çev. Hüseyin Özel. Ankara: Bilim ve Sanat Yayınları.

Giddens, A. (2000). Sosyoloji. Çev. H. Özel and C. Güzel. Ankara: Ayraç Yayınları.

Guclu, Idris \& Sevinc, Bilal. (2011). The impact of information society on terrorism and counterterrorism: A case study of Turkey. In S. Ekici (Eds.), Counter Terrorism in Diverse Communities. Amsterdam, Netherlands: IOS Press.

Haferkamp, H., \& Smelser, N. J. (eds) (1992). Social Change and Modernity. Berkeley: University of California press.

Hagen-Zanker, J. (2008). Why do people migrate? A review of the theoretical literature. A review of the theoretical literature. Maastrcht Graduate School of Governance Working Paper. https://doi.org/10.2139/ssrn.1105657

İçli, G. (2011). Sosyolojiye giriş. Ankara: Anı Yayınları.

İşüden, T., Ercan, F., \& Türkay, M. (1995). Gelişme iktisadı kuram-eleştiri-yorum. İstanbul: Beta Yayınlar.

Jacobs, G. \& Cleveland, H. (1999). Social development theory. Retrieved from http://www.icpd.org/development_theory/SocialDevTheory.htm

Kiray, B. M. (1999). Toplumsal yapı ve değişme. İstanbul: Bağlam Yayınları.

Kongar, E. (1981). Toplumsal değişme kuramlart ve türkiye gerçeği. İstanbul: Remzi Kitabevi.

Lenski, G. E. (1966). Power and privilege: A theory of social stratification. Chapel Hill: University of North Carolina Press. 
Lenzer, G. (2004). The essential writings; Auguste Comte and positivism. New Brunswick: Transaction Publishers. Özdemir, Ş. (1988). Türkiye'de toplumsal değişme ve çevre sorunlarına duyarlılık. Ankara: Palme Yayınları.

Pareto, V. (1935). The mind and society. Ed. Arthur Livingston.

Pareto, V. (1991). The rise and fall of the elites: An application of theoretical Sociology. Transaction Publishers.

Reeler, D. (2007). A Three-fold Theory of Social Change. Community development.

Smith, A. D. (1996). Toplumsal değişme anlayışı. Çev. Ülgen Oskay. Ankara: Gündoğan Yayınları.

Yaka, A. (2011). Sosyal değişme türk modernleşmesi. İstanbul: Gündoğan Yayınları. 